\title{
ENTRE A PSICOGÊNESE E A LINGUÍSTICA: UMA ANÁLISE EM AQUISIÇÃO DE LINGUAGEM ESCRITA DE CRIANÇAS EM PROCESSO DE ALFABETIZAÇÃO
}

\author{
Maria Aparecida Ramos Lima ${ }^{1}$ \\ Dennys Dikson ${ }^{2}$
}

\begin{abstract}
Resumo: Este trabalho apresenta, discute e analisa a aquisição de linguagem escrita em produçóes de atividades escolares de crianças em processos de alfabetização em uma turma de $2^{\circ}$ ano do Ensino Fundamental I de uma Escola Municipal de Solidão-PE. Trouxemos, num primeiro plano, a teoria da Psicogênese da escrita, com Ferreiro e Teberosky (1999), e, num segundo, a da Aquisição da Linguagem Interacionista, através de De Lemos (1992, 1995), de Borges (2006, 2010), dentre outros, com o intuito de compreender o processo de construçáo escrita de um mesmo texto sob a ótica de duas noçôes que possuem lugares antagônicos de compreensão, revelando-se algumas proximidades e robustos distanciamentos. O estudo carrega um foco de abordagem qualitativa, crítica e reflexiva, com aplicação de atividades escritas em ambiente escolar, fomentadas por alunos em processo de aquisição inicial. A partir dessa bifurcação teórica, analisamos um único texto de cada aluno primeiro a partir da Psicogênese e, logo depois, à luz da Aquisição de Linguagem Interacionista. As discussóes levadas à tona nos mostram o quanto cada teoria contribui no desenvolvimento de concepçóes acerca do sujeito, da língua, da linguagem e do próprio processo de aquisição escrita, situação que permite asseverar que os dados revelaram uma riqueza impressionante de significaçóes circundantes nas produçóes escritas das crianças, afastando, de certa maneira, uma escrita de um sujeito tido como psicologizante, aproximando-se mais de um processo de escritura tendo como lugar de origem este sujeito imerso e sob efeito do funcionamento da linguagem, sempre.
\end{abstract}

Palavras-chave: Aquisição de linguagem escrita. Psicogênese. Aquisição Interacionista. Atividades escolares.

1 Mestre em Letras pelo Programa de Pós-Graduação de Mestrado Profissional em Letras (PROFLETRAS) da Universidade Federal Rural de Pernambuco, Unidade Acadêmica de Garanhuns (UFRPE/UAG). Professora da Rede Municipal de ensino da cidade de Solidão-PE.

2 Doutor em Letras e Linguística pela Universidade Federal de Alagoas (UFAL). Estágio de Pósdoutoramento em Linguística. Docente do Departamento de Letras e do Mestrado Profissional em Letras (PROFLETRAS) da Universidade Federal Rural de Pernambuco, Unidade Acadêmica de Garanhuns (UFRPE/UAG). 


\title{
ENTRE LA PSICOGÉNESIS Y LA LINGÜÍSTICA: UN ANÁLISIS EN ADQUISICIÓN DE LENGUAJE ESCRITO DE NIÑOS EN PROCESO DE ALFABETIZACIÓN
}

\begin{abstract}
Resumen: Este trabajo presenta, discute y analiza la adquisición de lenguaje escrito en producciones de actividades escolares de niños en procesos de alfabetización en una clase de $2^{\circ}$ año de la Enseñanza Fundamental I de una Escuela Municipal de Solidáo-PE. En un primer plano, la teoría de la Psicogénesis de la escritura, con Ferreiro y Teberosky (1999), y, en un segundo, la de la Adquisición del Lenguaje Interaccional, a través de De Lemos (1992, 1995), de Borges (2006, 2010) , entre otros, con el fin de comprender el proceso de construcción escrita de un mismo texto bajo la óptica de dos nociones que poseen lugares antagónicos de comprensión, revelándose algunas cercanías y robustos distanciamientos. El estudio lleva un enfoque de enfoque cualitativo, crítico y reflexivo, con aplicación de actividades escritas en ambiente escolar, fomentadas por alumnos en proceso de adquisición inicial. A partir de esa bifurcación teórica, analizamos un único texto de cada alumno primero a partir de la Psicogénesis y, luego, a la luz de la Adquisición de Lenguaje Interaccionista. Las discusiones llevadas a la superficie nos muestran cuánto cada teoría contribuye en el desarrollo de concepciones acerca del sujeto, de la lengua, del lenguaje y del propio proceso de adquisición escrita, situación que permite aseverar que los datos revelaron una riqueza impresionante de significaciones circundantes en las producciones escritas de los niños, alejando, de cierta manera, una escritura de un sujeto tenido como psicologizante, aproximándose más a un proceso de escritura teniendo como lugar de origen este sujeto inmerso y bajo efecto del funcionamiento del lenguaje, siempre.

Palabras clave: Adquisición de lenguaje escrito. Psicogénesis. Adquisición Interaccional. Actividades escolares.
\end{abstract}

\section{BETWEEN PSYCHOGENESIS AND LANGUAGE: AN ANALYSIS IN ACQUISITION OF WRITTEN LANGUAGE OF CHILDREN IN LITERACY PROCESS}

\begin{abstract}
This paper presents, discusses and analyzes the acquisition of written language in the production of school activities of children in literacy processes in a class of 2nd year of elementary school I of a Municipal School of Solitude-PE. We have brought the theory of writing psychogenesis, with Ferreiro and Teberosky (1999), and in a second one, that of the Acquisition of Interactionist Language, through De Lemos (1992, 1995), by Borges (2006, 2010) , among others, in order to understand the process of written construction of the same text under the view of two notions that have antagonistic places of understanding, revealing some proximity and robust distances. The study carries a focus of a qualitative, critical and reflexive approach, with application of written activities in school environment, fomented by students in the process of initial acquisition. From this theoretical bifurcation, we analyze a single text of each student first from the Psychogenesis and, soon after, in the light of the Acquisition of Interactionist Language. The discussions revealed how much each theory contributes to the development of conceptions about the subject, language, language and the actual process of written acquisition, a situation that allows to assert that the data revealed an impressive richness of surrounding meanings in written productions of the children, moving away, in a certain way, a writing of a subject considered as a psychologist, approaching more of a process of writing having as place of origin this subject immersed and under the effect of language, always.
\end{abstract} Keywords: Acquisition of written language. Psychogenesis. Interactionist Acquisition. School activities. 


\section{Consideraçóes iniciais}

O presente trabalho traz um recorte de uma pesquisa que procurou investigar a aquisição de linguagem de crianças em estágio inicial de contato com a língua escrita, tendo como escopo e respaldo teóricos as noções da Psicogênese (FERREIRO; TEBEROSKY, 1999), de um lado, e, do outro, a Linguística com as questões tecidas pela Aquisição de Linguagem Interacionista (DE LEMOS, 1992, 1995; BORGES, 2006, 2010). Apresentamos análises em ambos campos do conhecimento, levando em consideração que, enquanto uma compreende a escrita numa visão psicologizante e representacionista, a outra se distancia, revelando na escrita uma relação de sujeito, língua e o (O) outro $^{3}$, atravessada por um funcionamento que escapa ao domínio do sujeito - discussões estas realizadas com o intuito de nos auxiliar a compreender como uma e outra teoria interpreta, entende e explora um mesmo movimento escritural inicial de alfabetização de crianças.

No âmbito dos estudos da aprendizagem da escrita, o reconhecimento da inscrição do processo de aprendizagem e o diálogo - mesmo que de certa forma antagônico entre si - nas perspectivas da Linguística e da Psicanálise, possibilita, sem dúvida, uma reflexão mais ampla sob vários aspectos, tendo em vista que a linguagem ocorre de maneira, sempre, multiforme e heterogeneamente, abrindo a possibilidade de observar as transformações/manifestações gráfico-textuais na escrita da criança, que comumente são desconsideradas pelas formas tidas como "tradicionais" da alfabetização.

Sob o prisma de um funcionamento linguístico-discursivo que as inclui (as multiformidades e heterogeneidades gráfico-textuais na/da aquisição em linguagem escrita), linguagem oral e linguagem escrita emergem numa relação de mútua constituição em que nem sempre conseguimos refletir sobre seus constructos, quando consideramos apenas um único viés teórico-metodológico de análise como ponto de partida.

E é nesse contexto que se justifica nossa intencionalidade, que perpassa por refletir, entre a Psicogênese e a Linguística, o processo de aquisição da linguagem nas produções escritas iniciais de crianças em processo de alfabetização, sempre partindo do processo de escritura de textos, em que sejam observadas ocorrências de "desvios", "erros", "falhas", "rabiscos", "riscos", "rasuras", "traços", "desenhos", "o não convencional" etc., que por vezes, ou quase sempre, passam despercebidos ou são descartados, por não se encontrarem em certos modelos idealizados pela escola ou em estruturas constituídas e sedimentadas por determinadas teorias de alfabetização, que, comumente, não consideram os efeitos de linguagens que há entre o sujeito e a língua.

É interessante lembrarmos que as discussões no âmbito da Aquisição da Linguagem - especificamente às que se voltam aos processos escritos iniciais de

3 Detalharemos mais adiante, na parte teórica. 
crianças $^{4}$ - tem sido marcada em sua maioria por teorias psicogenéticas, e mesmo algumas questões linguísticas, por vezes, aparecem sob esse mesmo prisma. Situação esta que nos absorve à fixação ou a determinado encaixamento em praticamente uma única abordagem teórico-metodológica desses processos de criação infantil, carregados de "erros" e "desvios", e que nos obrigaria a enxergar certas fases ou etapas na aquisição da escrita em que a criança deveria ou deve obrigatoriamente estar inserida, a depender de cada passo que vai ocorrendo na aprendizagem da escrita alfabética.

Dessa maneira, no decorrer do artigo, traremos algumas questões à luz dos trabalhos de Ferreiro e Teberosky (1999) e às vinculações de questões linguísticas à área de Aquisição da Linguagem, sobretudo ao esforço de teorização do Interacionismo realizado por De Lemos (1992, 1995), acompanhada, posteriormente, por Borges $(2006,2010)$ e outros.

A partir desses movimentos teóricos, analisaremos, assim, dois textos de escritas infantis iniciais, cuja ação prática foi realizada em aulas de Língua Portuguesa, em três momentos distintos, através de oficinas de produção de textos (detalhadas mais adiante na parte metodológica). O público atingido pela ação foi 22 alunos de um $2^{\circ}$ ano do Ensino Fundamental I, de uma escola pública municipal da cidade de Solidão-PE, os quais realizaram as produções escritas sem intervenções que incitassem a correção ou reformulação da escrita gráfica.

O que esperamos com os resultados obtidos através do diálogo entre as teorias elencadas, é fomentar contribuições acerca das concepções de aprendizagem no processo inicial da escrita de crianças em movimento de alfabetização; não só nos moldes clássicos que largamente conhecemos, mas, e principalmente, procurar conceber, entender e refletir acerca das relações diversas e possíveis entre língua e sujeito em seus processos de funcionamentos.

\section{Um passeio sobre a psicogênese}

Ferreiro e Teberosky (1999), inspiradas na base piagetiana, articulam a alfabetização como uma construção da representação conceitual da base alfabética em que a criança percorre uma sequência de fases. As autoras carregaram e carregam reconhecimento inquestionável na contribuição para a alfabetização, na tentativa de descrever o processo de escrita que as crianças perfazem até a alfabetização propriamente dita.

Há, sem dúvida, a tentativa de se dar um estatuto de escrita à criança, com novas dimensões que antes expressavam nitidamente a dicotomia que selecionava os estudantes em dois grupos: os alfabetizados e os não-alfabetizados. A partir

4 Não estamos aqui nos referindo a trabalhos que abordem discussões no âmbito da alfabetização e letramento, como é o caso, por exemplo, das investigações perquiridas por Soares (2008); ao contrário, diz respeito, na verdade, a pesquisas que levam em consideração tanto aspectos técnicos quanto teóricos especificamente dentro da aquisição de linguagem escrita. 
das autoras, e de seus trabalhos de porte psicogenético, o erro passa, então, a ganhar status no processo de alfabetização (a fazer parte do processo construtivo), revelando em qual fase a criança se aproxima ou se distancia de estar alfabetizado.

Considerando o sentido literal, a palavra Psicogênese pode se caracterizar como um estudo da origem e desenvolvimento dos processos mentais ou psicológicos, da mente ou da personalidade. Em um contexto mais amplo, cabe a reflexão acerca da investigação que descreve os passos e processos de aquisição da língua escrita por crianças em processo de alfabetização; discussões estas que ganharam uma roupagem bem mais robusta quando da publicação da obra Psicogênese da lingua escrita (FERREIRO; TEBEROSKY, 1999).

A literatura nos mostra que no início da década de 80, Ferreiro e Teberosky (1999) realizaram esse estudo com quase mil crianças sobre o desenvolvimento da linguagem escrita; investigações estas que culminaram nessa importante obra que apresenta etapas de evolução que as crianças perpassam por degraus dentro do processo de aquisição da língua escrita. A conjuntura histórica desse período, a partir desse vasto trabalho das autoras, vem se caracterizar por profundas mudanças no campo educacional da alfabetização de infantes.

Seguindo a esteira da psicologia de Piaget (1973), Ferreiro e Teberosky (1999) ganharam grande popularização no meio educacional brasileiro, tendo em vista que os resultados da pesquisa provocaram uma espécie de "revolução conceitual" na área da alfabetização. A visão central que norteava as teorias predominantemente associacionistas cede e abre espaço para novas discussões inspiradas num sujeito psicologizante, que consegue realizar a representação do mundo pela linguagem e que manipula essa linguagem com o fim de aprender, de se alfabetizar.

Inconteste que todas essas contribuições foram de suma importância para a área da alfabetização. Ao focar a escrita como um instrumento de conhecimento, desenvolveram uma investigação acerca da aquisição a partir de um parâmetro ao modelo de desenvolvimento cognitivo construtivo inaugurado por Piaget (1973). As autoras contrapõem-se ao modelo de estímulo resposta ${ }^{5}$ no qual o ensino associacionista correspondia a tais estímulos, entendendo que a criança em seu processo de alfabetização perpassa de um estágio a outro, construindo hipóteses lógicas em seu processo de apropriação da escrita alfabética.

Nesse contexto, a exposição e submetimento das crianças a textos que circulam socialmente e de forma interativa, podem levar à progressão de um nível a outro até culminar no processo alfabético de escrita. Independentemente da idade e/ou classe social, todas as pessoas alfabetizadas perfaziam tal processo.

Através dos resultados obtidos pelas autoras, com crianças de 4 a 6 anos, foram definidos cinco níveis de desenvolvimento da escrita. A partir do momento em que ela compreende para que serve a escrita, a criança realizaria um longo

5 Para melhor aprofundamento acerca do termo (estímulo-resposta), ler Skinner (2005).

Signos, Lajeado, ano 40, n. 1, p. 174-195, 2019. ISSN 1983-0378 
período caracterizado de níveis sucessivos (níveis ordenados) no desenvolvimento da escrita revelando suas hipóteses (FERREIRO; TEBEROSKY, 1999):

- NÍVEL 1: Conhecido como nível pré-silábico, nesse período as crianças possuem hipóteses bastante embrionárias sobre a escrita, podem considerar que escrever e desenhar são evidentemente a mesma coisa. É comum solicitarmos que o aluno escreva uma determinada palavra, por exemplo, CASA, e provavelmente ele represente a casa em forma de desenho, considerando que está escrito a palavra casa. É comum também nesse nível a utilização de letras e números, estas e outras constatações, caracterizam esse período. Misturar letras e números, desenhos, rabiscos, garatujas, pseudoletras, associar o nome do objeto ao tamanho, - por exemplo, a palavra BOI, poderia ser escrita com muitos caracteres, devido ao seu tamanho -, é muito comum nesse período.

- NÍVEL 2: Nesse período, ainda considerado pré-silábico (um pouco mais avançado), a criança não escreve com desenhos, usa letras, diferencia letras de números. Podem variar a posição na ordem linear das letras. Geralmente, utilizam a variedade de letras do próprio nome. A leitura é feita globalmente, e a escrita não faz correspondência com o valor sonoro da letra, palavra ou frase.

Essa variedade se justifica: "Para poder ler coisas diferentes (isto é, atribuir significados diferentes), deve haver uma diferença objetiva nas escritas. O progresso gráfico mais evidente é que a forma dos grafismos é a mais definida, mais próxima à das letras". (FERREIRO; TEBEROSKY, 1999, p.202).

- NÍVEL 3: Considerada hipótese silábica. É possível nesse nível observar duas importantes hipóteses: a primeira o aluno pode atribuir adequadamente a quantidade de letras de uma palavra, ainda que não as relacione à sua correspondência fonológica (quando ele escreve uma letra para cada sílaba), porém não necessariamente tenha correspondência fonética, ou seja, ao ser solicitado a escrever a palavra ESCOLA, por exemplo, é possível que ele escreva: MTO. E a segunda hipótese, quando ele utilizada qualitativamente uma letra para a pauta sonora (uma letra para cada sílaba), ou para cada palavra em uma frase dita, corresponderá respectivamente ao seu valor sonoro. Ao ser solicitado a escrever a palavra ESCOLA, por exemplo, é possível que ela escreva: EOA ou ainda SCL.

- NÍVEL 4: Aparece a hipótese em que podemos classificá-la de silábicoalfabético; é o processo de transição do silábico para o alfabético.

Passagem da hipótese silábica para a alfabética... a criança abandona a hipótese silábica e descobre a necessidade de fazer uma análise que vá "mais além" da sílaba pelo conflito entre a hipótese silábica e a exigência de quantidade mínima de granas (ambas exigências puramente internas, no sentido de serem hipóteses originais da criança) e o conflito entre as formas gráficas que o meio lhe impõe e a leitura dessas formas em termos de hipótese silábica (conflito entre uma exigência interna e uma realidade exterior ao próprio sujeito). (FERREIRO; TEBEROSKY, 1999, p. 214 - grifos da autora). 
Nesse nível a criança produz uma escrita em que ora escreve sílabas que correspondem ao sistema silábico alfabético, ora representa apenas uma letra (consoante ou vogal) que corresponde ao alfabeto. É uma escrita "quase" alfabética. Com a exemplificação do nível anterior com a palavra ESCOLA, possivelmente, diante das possíveis variedades, é possível que ela escreva: ECOA ou ainda ESCOL, etc.

- NÍVEL 5: Considerado o último nível no processo de alfabetização, a criança já descobriu que cada letra pode representar um som da fala e que é preciso juntá-las de um jeito que formem sílabas de palavras e assim sucessivamente.

A escrita alfabética constitui o final dessa evolução. Ao chegar a este nível, a criança já franqueou a "barreira do código"; compreendeu que cada um dos caracteres dá escrita corresponde a valores sonoros menores que a sílaba e realiza sistematicamente uma análise sonora dos fonemas das palavras que vai escrever. Isto não quer dizer que todas as dificuldades tenham sido superadas: a partir desse momento, a criança se defrontará com as dificuldades próprias da ortografia, mas não terá problemas de escrita, no sentido estrito. (FERREIRO; TEBEROSKY, 1999, p.219, grifos da autora).

Conforme se observa, nesse período considerado o último nível - alfabético, inicialmente escrevem com fortes marcas da oralidade; contendo diversos desvios de segmentação; e ortografia, comumente, desprendida do que se tem na convenção.

De acordo com esses, as crianças são capazes de construir sistemas interpretativos e criar hipóteses na busca de soluções para compreender e manipular a escrita - sem dúvida, essa é uma das diferenças da concepção da natureza do escrevente na visão de Ferreiro e Teberosky (1999) em relação à visão que se tinha presente na prática escolar de alfabetizadores, revelando uma importante contribuição do trabalho para o campo educacional.

Até chegar a esse último nível, a criança perpassa por várias fases, revelando suas hipóteses pelos diferentes níveis da escrita. Digamos que durante todo esse processo de aquisição da língua escrita, há um caminho bastante vasto para ser descoberto e que pode direcioná-la para a busca da construção de uma escrita dita convencional, e, nesse caso, a família, a escola e o professor têm um papel fundamental na construção desses saberes.

Ainda nesse campo, a relação com a linguagem e a escrita, acontece muito antes da chegada da criança à escola (FERREIRO E TEBEROSKY, 1999). De fato, a criança é rodeada de textos dos mais variados contextos discursivos, principalmente fora do espaço de sala de aula. As autoras apregoam que a escrita é concebida de duas formas distintas: representação da linguagem ou como código de transcrição gráfica, enfatizando que mediante a forma de discernimento com o qual encaramos as duas acepções em torno da escrita, poderá ocasionar consequências pedagógicas dicotômicas que dividem a alfabetização: se compreendida somente como código de transcrição gráfica, podemos associá-la a aquisição de uma técnica (um código); 
compreendida somente como um sistema de representação, a aprendizagem pode se converter na apropriação de um novo objeto de conhecimento.

Essas duas acepções nos remetem ao outro objeto de estudo desse trabalho: considerar a escrita ou como uma técnica a ser adquirida ou como aprendizagem conceitual, impossibilita uma análise que desconsidere as relações entre a criança que produz e o texto que é produzido por ela - sujeitos indissociáveis em suas relações. Vejamos o que a Linguística trata sobre o tema.

\section{Aquisição da linguagem: uma perspectiva linguística}

A relação do sujeito com a linguagem oral e/ou escrita é fruto de férteis estudos e pesquisas que vislumbram sua compreensão. As revoluções conceituais no campo da linguagem ao longo dos tempos têm provocado profundas reflexões sobre as concepções de língua e linguagem, ocasionado mudanças de olhares sobre o funcionamento seja da fala ou da escrita.

Nesse aspecto, é preciso situar, de antemão, que Interacionismo ${ }^{6}$ iremos percorrer. O deslocamento de olhar sobre a Aquisição da Linguagem nesse contexto que ora se insere este trabalho, repousará seu acento teórico sob as abordagens construídas e forjadas por De Lemos (1992, 1995, 2000, 2006, entre outros) que, através do encontro com a Psicanálise matizada pela releitura que Lacan fez dos trabalhos de Saussure e Jakobson, busca incluir o sujeito nas reflexões com a língua e assume um compromisso com a chamada ordem própria da língua, na qual o próprio sujeito é efeito de linguagem e não lugar psicologizado de controle desta.

A fala de crianças à qual De Lemos se reporta em seus diversos trabalhos de aquisição da linguagem aponta a possibilidade de considerar as relações subjetivas com a escrita, foco deste trabalho, abrindo-nos um campo úbere de investigação, a qual embasará as discussões sobre a concepção de língua e linguagem. Nesse sentido, Borges $(2006,2010)$ deixa bem evidente essa possibilidade de intercruzamento teórico especificamente em investigações apontadas ao campo da escrita de crianças em processos de alfabetização na sala de aula, abordando as relações entre Psicanálise, arte e escrita, nas diversas nuances de subjetivação.

Filiamos, dessa maneira, nossa pesquisa à proposta do Interacionismo dialógico de base teórica de De Lemos (1992 e 1995) e Borges (2006 e 2010), que tratam da interação entre a criança e o adulto, em que o Outro da teoria psicanalítica é tomado como lugar do funcionamento da língua ocupado pelo outro (semelhante). Essa especificidade instaura uma direção singular para os estudos que se ocupam da investigação acerca da aquisição da linguagem pela criança - referimo-nos a uma teoria em movimento, que não dá conta unicamente do "produto final", mas do processo em funcionamento da linguagem, lugar do olhar, em que os processos

6 O termo "Interacionismo" assume diferentes nuances nas diversas abordagens linguísticas. Referimo-nos aos trabalhos de De Lemos, largamente citados neste artigo. Portanto, não deve ser confundido com a proposta interacionista de Piaget e/ou Vygotsky. 
constitutivos, segundo De Lemos (1992), devem considerar um sujeito efeito de linguagem, e não manipulador dela.

O sujeito aqui vislumbrado emerge da Psicanálise lacaniana, no qual é visto não unicamente como posição ou função que afetam o sujeito, mas nas quais se constitui o sujeito clivado pelo inconsciente submetido pela linguagem. Nesse caso, temos algo invertido: não se parte do Interacionismo a partir do sujeito e/ou objeto conforme as teorias cognitivistas abordadas anteriormente, em que existe algo real estruturado, mas da linguagem, esta como funcionamento, tendo um sujeito enquanto seu efeito.

Daí o desígnio ao Interacionismo dialógico pelas possibilidades de entender a escrita da criança como uma cadeia de significantes (BORGES, 2006); nessa cadeia, a criança ainda que não alfabetizada, pode revelar o conhecimento da sistematicidade e o funcionamento da linguagem escrita no processo linguístico da língua, em que se faz presente o "outro (semelhante)" e o "Outro (linguagem)".

Considerando a noção lacaniana deslocada para a Aquisição de Linguagem por De Lemos. Segundo Lier-de-Vitto e Carvalho (2007, p. 18), o "Outro - língua que constitui o sujeito a partir dos efeitos de captura do seu (Outro - língua) funcionamento" em que a ordem própria da língua compreende a tríade estrutural, fundamental ao processo de aquisição da linguagem, em que se apresenta a criança, pelo outro(semelhante) - pessoa do convívio e pelo Outro/língua em funcionamento.

A autora aponta que a "constituição do objeto - a escrita da criança se dá na passagem pela escrita do Outro, pela via do espelho, ou seja, das apropriações e capturas significantes" (BORGES, 2010, p. 99).

A abordagem de De Lemos $(1992,1998)$ traz uma importante contribuição no campo da Aquisição de Linguagem por apresentar o reconhecimento da ordem própria da língua, e também por privilegiar o que os dados mostram e, partindo deles, interrogar. Borges $(2006,2010)$, comungando com esses postulados, nos mostra que "há um deslizamento incessante do significado sob o significante e é a rede dos significantes, pelas relações que nela se constituem que vai possibilitar o efeito de sentido" (BORGES, 2006, p.184). O desejo do sujeito desliza incessantemente de um objeto para outro, numa relação guiada pelo caminho que a linguagem lhe indica. Essa posição justifica sua adesão a Lacan (1998) que, ao introduzir a Linguística na Psicanálise como elemento fundamental, afirma que a linguagem determina o sentido engendrando as estruturas do pensamento.

7 Conforme afirma Lacan (1962), o Outro com letra maiúscula não é um sujeito, é um lugar no qual se esforça - diz Aristóteles - por transferir o saber do sujeito. [...] O Outro é o depositário representativo desta suposição de saber e é isto o que chamamos inconsciente, na medida em que o sujeito se perdeu, ele mesmo, nesta suposição de saber (1962, p. 7). De forma mais corriqueira, poderíamos até dizer que o "Outro" perpassa pelo o próprio funcionamento da linguagem, ou melhor, é o funcionamento da linguagem afetando o(s) sujeito(s). 
No item seguinte, ao analisarmos os textos escritos pelos alunos, destacaremos os enfoques sob duas vias de olhares, na perspectiva da Psicogênese e na da Linguística, com o intuito de elencar as contribuições e distanciamentos de cada teorização elencada anteriormente.

\section{Caminho metodológico}

Diante dos nossos anseios, foram desenvolvidas três oficinas de produção textual que deram luz aos textos que compõem o nosso corpus. Vale ressaltar que as três oficinas fizeram parte de sequências didáticas ${ }^{8}$, ou sequências de atividades escolares, realizadas em parceria com a professora da turma $\left(2^{\circ}\right.$ anos), durante $\mathrm{o}$ ano de 2018.

Fruto dessas vivências, as atividades de escrita focaram, na primeira oficina, o gênero crachá; na segunda, o gênero certidão de nascimento; e na terceira oficina, o gênero lista ${ }^{9}$. Dentre essas oficinas, selecionamos duas produções para análise neste trabalho, corpus este oriundo da segunda oficina. As análises serão realizadas dentro de uma abordagem qualitativa, com metodologia de discussão que perpassa - como inclusive já apontamos mais acima - pelo olhar aos textos escritos pelas crianças, primeiro, a partir do que a Psicogêneses pode nos dizer daquelas produção, e, após, o que o Interacionismo Dialógico pode nos auxiliar a enxergar nestas escritas iniciais, de forma que seja levada em consideração, também, a relação sujeito, língua e o outro.

O segundo texto feito pelas crianças nasceu a partir de uma imagem fotográfica de uma ultrassonografia de um bebê no ventre (Figura 1). Os alunos foram convidados a produzirem seu próprio texto, com o título"minha HISTÓRIA de vida".

8 Não aprofundaremos conceitos alusivos ao termo sequência didática por não ser objeto de estudo e análise desta pesquisa. Para melhor compreensão sobre, sugerimos a leitura de Cosson (2012); Dolz, Noverraz s Schneuwly (2004); e Zabala(2007).

9 Por conta do espaço que dispomos aqui, não há como detalhar todo projeto. 
Figura 1:imagem de ultrassonografia

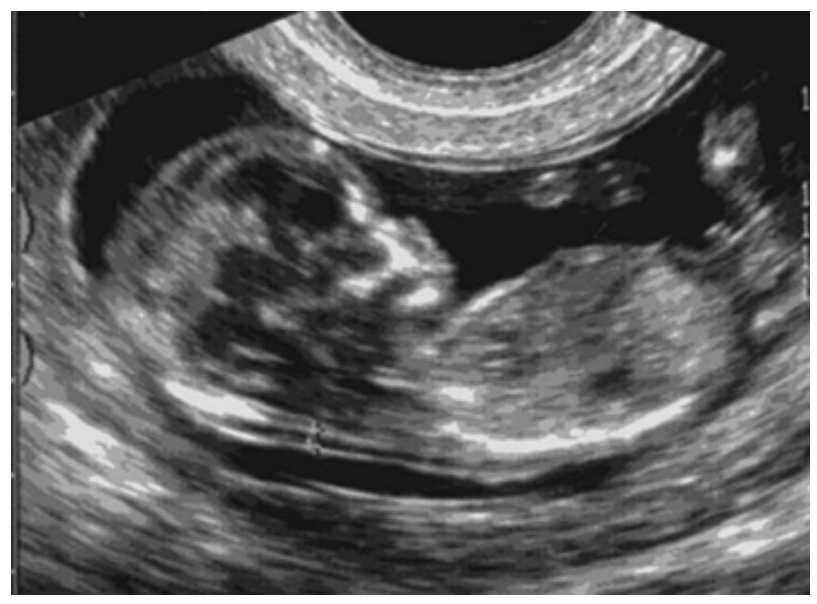

Fonte: Livro de história - Porta aberta, $2^{\circ}$ ano, 2014.

A disposição dos textos para análise está organizada da seguinte maneira:

- Identificação dos textos através de: ESTUDANTE 1 - E1; e ESTUDANTE 2 - E2. Texto escaneado do estudante, sem alterações. Enumeração de linhas. Transcrição da leitura do aluno (CAIXA ALTA), feita logo abaixo do texto escaneado. Texto marcado com formas para facilitar a análise dos fenômenos observáveis.

É muito relevante ressaltar que, nas interpretações expendidas, também levaremos em consideração, além do texto escrito, a leitura que a criança faz do próprio texto que escreve. Essa metodologia é bem específica ao nosso trabalho, e serve como lugar de observação bifurcado - texto e leitura, juntos.

\section{A revelação dos dados além das representaçóes gráficas}

A Aquisição da Linguagem corresponde a uma área de investigação da Linguística. Esta, enquanto ciência, abre diversas possibilidades que vão além da descrição e explicação única da fala/escrita da criança. É preciso considerar um "instrumental" de aproximação peculiar entre os fenômenos da aquisição da linguagem, pois esta

exige dos estudiosos que o assumem, uma séria reflexão sobre o custo teórico de excluir as questões textuais e discursivas de sua investigação sobre a língua. Maior é esse custo quando a essa exclusão se alia uma noção de desenvolvimento que coloca a criança como um sujeito diante da língua como objeto, impedindo a apreensão do processo de Aquisição de Linguagem como um processo de subjetivação (DE LEMOS, 1995, p. 27, grifo nosso)

Para tanto, podemos dizer que, na perspectiva interacionista, a criança é capturada pelo funcionamento da linguagem por meio da interação de sua fala com 
a do adulto. Desse modo, o que prevalece na fala são as marcas da fala do adulto com quem ela tem contato.

Levando isso em consideração, o corpus desta análise é constituído por quatro manuscritos de escritas iniciais feitos por crianças de 7 e 8 anos de idade do $2^{\circ}$ ano do primeiro ciclo, ambas em processo de alfabetização.

Para entender a escrita destas crianças, tomamos o texto "A aquisição da escrita como processo linguístico" (Borges, 2006), no qual a autora afirma que a criança no processo de aquisição da escrita, conduzida pelo adulto, é colocada em contato com textos, fazendo com que o sujeito da Psicologia, do conhecimento, ceda espaço ao da Psicanálise, o qual é "alienado ao discurso do Outro" (BORGES, 2006, p.149); esse "Outro", segundo Lacan (1983), corresponde ao lugar do simbólico do funcionamento da linguagem.

Os mesmos textos são refletidos também à luz da Psicogênese, nos quais faremos uma análise quanto às "fases" em que se encontram essas produções mediante os postulados de Ferreiro e Teberosky (1999) e Morais (2012). Esperamos dessa forma, encontrar dentro de cada teoria abordada os caminhos apontados pelos "erros", "lapsos", "simulacros", "desvios"... Entre outros fenômenos.

Segue a produção do E1:

Figura 2:Escrita de texto com transcrição - E110

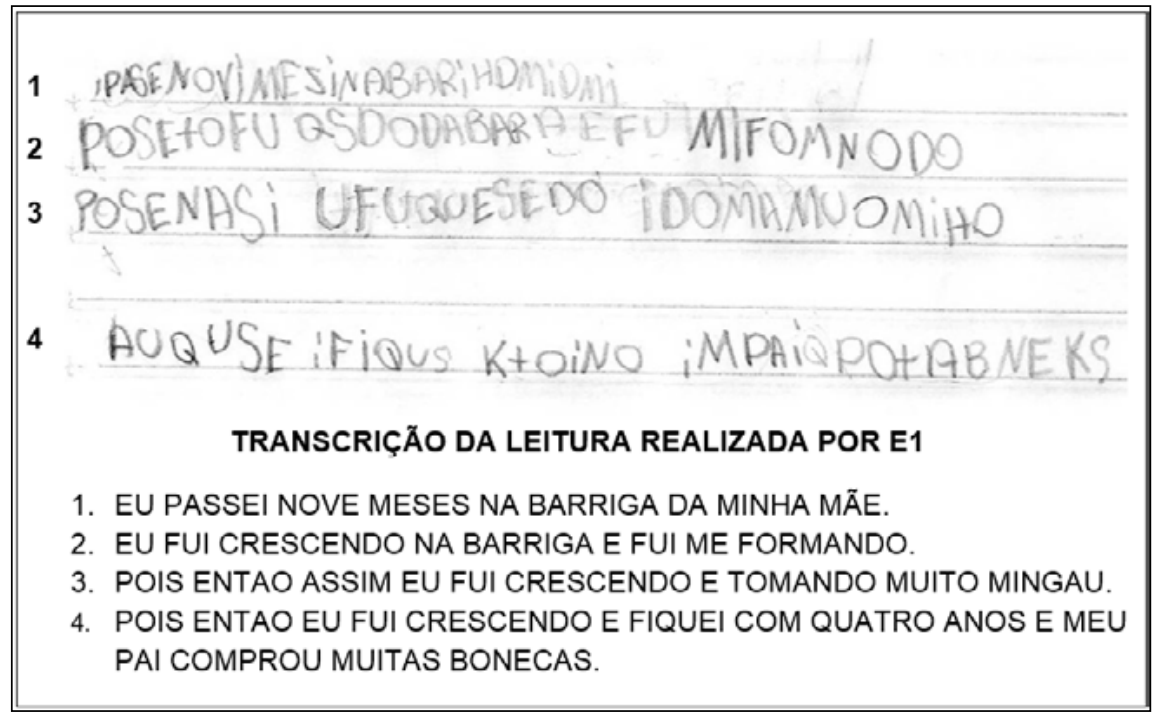

Fonte: arquivo próprio da pesquisa

10 Conforme dito anteriormente, essa transcrição foi escrita a partir da leitura que a criança fez do próprio texto. Dessa mesma forma segue a transcrição ao lado do próximo texto, o do E2. 
Levando em conta as investigações apresentadas pela Psicogênese (FERREIRO; TEBEROSKY, 1999), acerca da evolução da escrita no processo de alfabetização, pode-se perceber neste corpus a classificação dessa escrita como sendo de nível 4, caracterizada pela passagem da hipótese silábica para a alfabética.

Nesse nível, a criança inicia um processo de "superação" da hipótese silábica ${ }^{11}$, em que se atribui um caractere para uma sílaba, passa a fazer uma leitura termo a termo(não global), consegue fazer combinações de vogais e consoantes numa mesma palavra, tentando combinar sons, sem tornar, ainda, sua escrita totalmente alfabética. É visível na linha 1 essa hipótese: ora a criança atribui letras correspondentes ao valor sonoro em sua totalidade, "NOVI" - NOVE, "MEZI" - MESES, ora oscila na escrita de forma que emprega apenas uma letra para a correspondência silábica "BARIH"- BARRIGA, "MI"- MINHA, "MI"- MÃE. Essa mesma dinâmica de escrita são notadas nas demais linhas: linha 2: "FU" - FUI, "QSDO" -CRESCENDO, "BARA" -BARRIGA, "FOMNODO" FORMANDO; Na linha 3: "POS" - POIS, "ENA" - ENTAO, "ASI" - ASSIM, "U" - EU, "FU" - FUI, "QUESEDO" - CRESCENDO, "DOMA" TOMANDO, "MUO" - MUITO, "MIHO" - MINGAU e assim segue uma escrita regular deste nível na linha 4: "QUSE" - CRESCENDO, "FIQS" - FIQUEI, "KTOQUATRO, "INO" - ANO, "M" - MEU, "PAI" - PAI, "QPO" - COMPROU, "TA" -MUITAS, "BNEKS" - BONECAS. Conforme explicitado anteriormente, esse nível de escrita, conforme Ferreiro e Teberosky (1999), corresponde ao

Conflito entre a hipótese silábica e as formas fixas... é importante que se perceba claramente a extraordinária riqueza deste momento de passagem e o difícil que se torna, para a criança, coordenar múltiplas hipóteses que foi elaborado no curso desta evolução...a criança elaborou duas ideias importantes, que resiste - e com razão - em abandonar: que faz falta uma certa quantidade de letras para algo que possa ser lido (ideia reforçada agora pela noção de que escrever algo é ir representado, progressivamente, as partes sonoras desse nome), e que cada letra representa uma das sílabas que compõe. (FERREIRO E TEBEROSKY 1999, p. 217).

Percebe-se que a criança começa a entender que a sílaba não é a menor unidade sonora e que não basta uma letra por sílaba, passando a oscilar escritas silábicas com escritas parcialmente alfabéticas.

Essa mesma visão é notável em Ferreiro (1995), para ingressar no que denominou de "período de fonetização da escrita", que se inicia no nível silábico e culmina no alfabético. A criança precisará ser posta a condições de reflexão fonológica, estabelecendo relações entre a escrita e a pauta sonora, da segmentação de palavras orais em sílabas, comparação de palavras quanto ao tamanho e às suas semelhanças sonoras. Essa sugestão resolveria a princípio a escrita sem segmentação do texto escrito da E1, pois, conforme verificamos, escreve seu texto com as palavras praticamente em sua totalidade, "juntas".

11 Conforme anteriormente apontado, nossas análises seguem pela escrita em constituição com a leitura feita de seu próprio texto pela criança, como se vê nas transcrições. 
Nesse caso, é comum quando as crianças começam a produzir autonomamente os seus textos iniciais que não consigam separar convencionalmente as palavras de um enunciado, escrevendo-as emendadas, como verificamos na L1 do texto acima "IPASENOVIMEZINABARIHDMIDMI" - EU PASSEI NOVE MESES NA BARRIGA DA MINHA MÃE, o que revela o desconhecimento da necessidade de deixar espaços entre grupos de letras que denominamos "palavra".

Diante da escrita do "G", antes de A, O e U apresentar o som "Guê", E1 faz a troca pela consoante fricativa glotal " $H$ ", valendo-se do recurso da transcrição fonética da letra $H$ "agá", a qual corresponde à sonoridade da letra "G", o que indica haver uma mistura realizada pela criança entre o fonema e o próprio nome da letra. Observamos na escrita da palavra L1 "BARIH" - BARRIGA e L3 "MIHO" - MINGAU, uma constatação perfeitamente plausível no processo de alfabetização em que as crianças valem-se de algum conhecimento que já tem, para escreverem. Tal aspecto se torna perfeitamente evidenciado em outras trocas de letras conforme sonorização ou aspecto gráfico semelhante.

Observando, agora, o corpus produzido por E1, a partir da Aquisição Interacionista, vamos notar que o outro assume aqui um lugar de destaque, composto pela criança, o outro e o Outro; este último sendo o polo dominante em alguns momentos, conforme revela a produção escrita.

Ao analisar o texto, percebem-se alguns simulacros diante da composição escrita. Ao ser solicitado a ler o que "escreveu" a criança desliza seu dedo rapidamente sobre a escrita decifrando-a conforme sua cadeia de significantes, de forma que em alguns momentos ela lê alguns conectivos, porém não estão presentes na escrita, demonstrando "que a criança representa a língua escrita pela constituição de um simulacro que, de certo modo, confere-lhe estabilidade, ainda que imaginária" (BORGES, 2010, p. 98); verificamos isso na linha 4: "POIS ENTAO" é imaginariamente lido, porém não está visivelmente escrito. Ainda na mesma linha o conetivo "COM", que tem a função de ligar os elementos, é lido e acontece o mesmo fenômeno anterior - não visualizamos sinais de sua escrita, nesse sentido, a significação é presente na medida em que a criança ressignifica suas produções e assume a posição de intérprete de si mesma e do outro, De Lemos (1992). Outro fato interessante é a escrita inicial de cada frase que compõe o texto: 
Figura 3: Escrita de texto com transcrição - E1

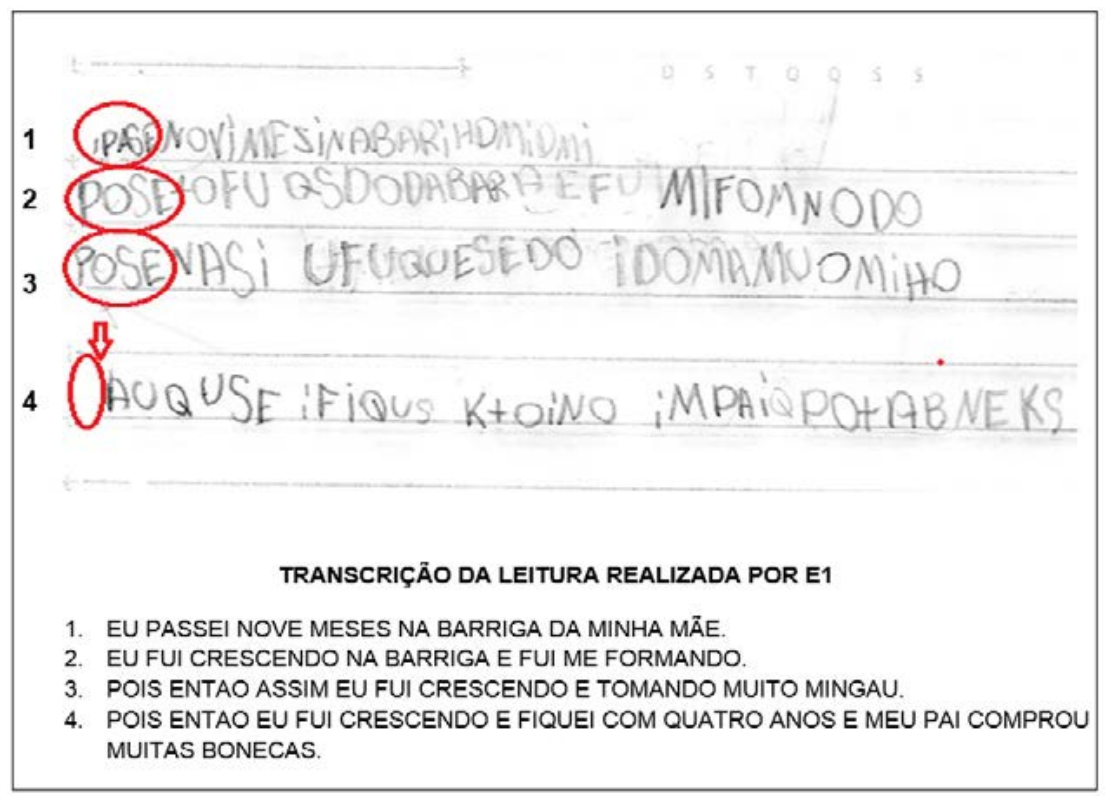

Fonte: arquivo próprio da pesquisa

Ao observamos a construção inicial das frases que compõem o seu texto, as palavras iniciais "POIS ENTÃO" não são reveladas na leitura feita na linha 1, e por acaso coincidem com a escrita "IPASE" - EU PASSEI, lida pela criança normalmente. $\mathrm{Na}$ sequência da linha 2 mais uma vez o texto apresenta a mesma grafia, contudo não coincide com a escrita e não é lido pela criança o que nos causa estranhamento inicialmente. Conforme combinamos a princípio junto à professora, não faríamos intervenções nas escrita e leitura. Seriam construções espontâneas e, a leitura, natural. Em caso necessário, dialogaríamos para que as realizassem. Contivemo-nos nesse momento e solicitamos a leitura da linha 3 na qual a criança realiza uma leitura por sílabas: "POSEN" - POIS ENTÃO. A mesma leitura é feita no simulacro (falta de caracteres representativos de escrita) presente na linha 4 quando ela inicia pronunciando as palavras "POIS ENTÃO".

Várias são as indagações nesse momento. $\mathrm{O}$ que a categorização dessas ocorrências nos permite avançar na compreensão da relação do sujeito com a linguagem? A escrita e a leitura das palavras que iniciam as linhas 3 e 4 explicariam o mesmo fenômeno na escrita presente no início das linhas 1 e 2 , ainda que não lido pela criança? Que movimento é esse em que ora a criança não pronuncia as palavras, mas estão escritas em seu texto (linhas 1e 2), ora ela pronuncia na leitura, porém não está visivelmente escrita (linha 4), ora ela escreve e realiza a leitura que se correspondem alfabeticamente (linha 3)? Para Borges (1995), a natureza do objeto de estudo da alfabetização, a língua escrita, implica o reconhecimento da sobredeterminação da ordem própria da língua sobre o sujeito. Assim os "erros", 
"problemas" na escrita da criança dizem respeito ao saber inconsciente e não a um déficit de aprendizagem.

Trata-se, pois, de um movimento de/na linguagem. Isso faz toda a diferença quando se pensa no estatuto do erro e do acerto nas produções das crianças. Esse lapso presente na leitura, porém ausente na escrita (linha 4), nos remete ao conceito de lapso freudiano, que, como parte integrante das discussões em nossa cultura, significa a revelação involuntária de desejos e sentimentos pessoais. Lacan (1957) considera esses lapsos como o inconsciente estruturado enquanto linguagem, ou seja, para ele, o inconsciente possui estrutura de funcionamento semelhante à linguagem. Alguns desses fenômenos também são registrados no texto do estudante $\mathrm{E} 2$.

Abaixo, agora, o manuscrito de E2. Essa produção, conforme discriminação na metodologia, surgiu de uma situação de produção textual em que foi solicitada a escrita de uma lista com os personagens da história do livro "Quem vai ficar com o pêssego?".

Figura 4: Escrita de texto com transcrição - E2

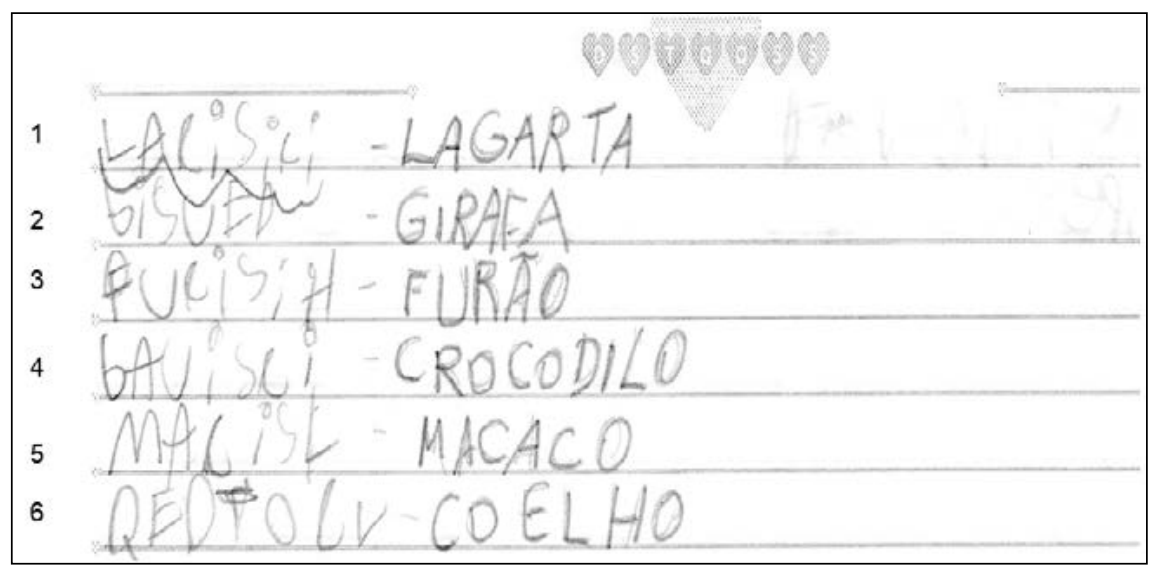

Fonte: arquivo próprio da pesquisa

Conforme os fundamentos de Ferreiro e Teberosky (1999) e Morais (2012), o estudante no processo de alfabetização perpassa um longo período, revelando diferentes níveis/hipóteses lógicas em relação à escrita antes de estarem alfabetizadas. Baseados nessas teorizações, o texto do aluno revela uma escrita típica do nível pré-silábico. Sabemos que esse nível pode ser representado de várias formas, desde o desenho, a garatuja, até a letra, mesmo que ainda não faça nenhuma correspondência entre o grafema e a correspondência sonora.

O texto desse estudante revela uma escrita dentro desse nível em um processo avançado, pois a criança já abandonou a fase do desenho e da garatuja. Ela já compreende que "[...] para poder ler coisas diferentes (isto é, atribuir significados diferentes), deve haver uma diferença objetiva nas escritas". (FERREIRO e 
TEBEROSKY, 1999, p. 202). É o que acontece com a escrita desse texto, nas linhas de 1 a 5 , apresentou-se uma variedade de letras, diferenciando um grafismo do outro, não usando o mesmo repertório de letras, garantindo que a palavra fique diferente, uma escrita da outra, e ainda utilizou apenas as letras do seu nome devido à familiaridade e as formas fixas.

Nesse nível de escrita a criança ainda não faz a correspondência entre a grafia e a sonoridade linguística, apenas faz correspondência a recortes ou letras de seu repertório: "o bonito ao enveredarmos por esse território antes desconhecido é desvendarmos que, sim, 'há muita vida', há muito trabalho cognitivo no período pré-silábico". (MORAIS, 2012, p. 54).

Nesses postulados, temos alguns desafios em enquadrar o estudante nesse nível, diante de uma escrita que apresenta muitas oscilações. Conforme se verifica na escrita que se consolida com a leitura, a primeira letra de cada palavra corresponde exatamente a correspondência sonora da escrita e da leitura feita. Verificamos isso nas linhas 1: "LACISCI" - LAGARTA, linha 2: "GISUED" - GIRAFA, linha 3: "FUCISIH" - FURÃO, linha 5: "MACISL" - MACACO e linha 6: "QEDTOLV" - COELHO.

No caso da escrita inicial das linhas 2 e 4 há uma semelhança na escrita do desenho da letra as quais aparentam com um $G$, porém essa semelhança icônica desaparece à medida em que são feitas as leituras seguintes das linhas 5, e 6 em que o estudante mantém um padrão regular no emprego da letra inicial das palavras, empregando na linha 5: "M" - MACACO, Linha 6: "Q" - COELHO.

Podemos afirmar que esta produção revela um processo de transição para o nível seguinte considerando a escrita e a leitura da sílaba inicial de cada palavra. No entanto, as sílabas medianas e finas, linhas 1: "LACISCI" - LAGARTA, linha 2: "GISUED" - GIRAFA, linha 3: "FUCISIH" - FURÃO, linha 5: "MACISL" - MACACO e linha 6: "QEDTOLV" - COELHO, são escritas conforme denominações típicas de nível pré-silábico em que o estudante recorre a letras consolidadas em seu repertório, sem fazer nenhuma correspondência silábica, o que muitas vezes torna difícil quando analisamos com o intuito apenas de enquadrar tal texto em determinado nível.

A variação de letras revela um efeito em que a criança procura imprimir no papel uma determinada organização ou sistematização de letras ou palavras, sempre na ordem de sua subjetividade. Esse fenômeno seria o "efeito do outro-discurso (escrito)" (BORGES, 2010, p. 106) sobre a escrita da criança. Nesse caso, o efeito do nome próprio que vai se revelando na lista de palavras de seu texto escrito, conforme se observa: 
Figura 5: Escrita de texto com transcrição - E2

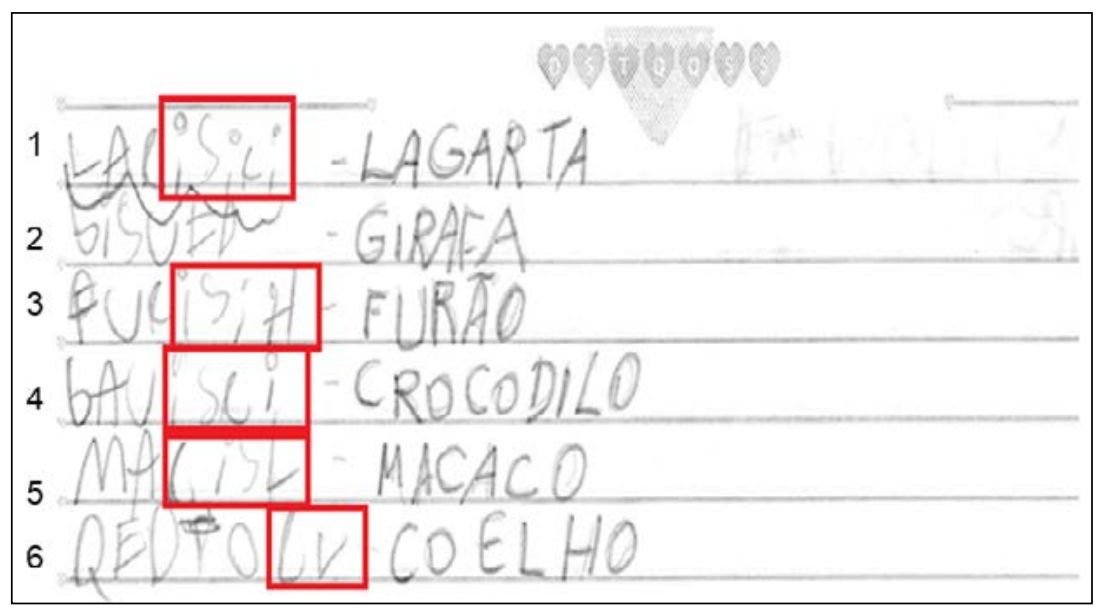

Fonte: arquivo próprio da pesquisa

Esse fenômeno revela a presença do Outro nessa produção. Após ao final da leitura feita, fizemos com o estudante e com a professora uma conversação que nos revelou o nome completo do aluno. Parte do nome é vislumbrada na escrita presente nas linhas 1,3, 4, 5 e 6 das sílabas finais das palavras, fato comum à utilização de letras que compõem o repertório do nome próprio.

Remetemo-nos também à concepção lacaniana de signo, no qual o significante exerce autonomia sobre o significado, dado que esta criança desliza de significante em significante, dando ênfase aos signos I, S, I, L, V que compõem a última palavra do nome próprio, confirmando tanto a presença do Outro (quando não escreve seu nome completo, mas confirma-se na escrita das palavras), quanto o rompimento dessa presença, na medida em que o imaginário passa ao simbólico, constituindo-se como um "eu" que se afirma pela presença de signos de seu nome próprio.

É importante investigar, perguntar, refletir, entender o processo, as relações existentes e as cadeias de significantes que se fazem presentes nas produções. O jogo simbólico em que as palavras "ganham" ou "perdem" letras e vão se transformando em escrita constituída revela nesses textos em análise efeito de escritas imprevisíveis, as quais transgridem os padrões convencionais da língua e em muitos casos são escritas desconsideradas pelos professores.

\section{Consideraçóes finais}

Quando nos propusemos à pesquisa no âmbito educacional, fomos incansavelmente indagados a refletir sobre nosso objeto e nosso objetivo. Há um vasto campo de possibilidades de discussões sobre a aquisição da escrita, mas por hora é possível dizer que o que foi exposto até aqui é parte de uma tentativa de deslocamento em duas vias. De um lado, tentamos olhar a aquisição da língua falada para a língua escrita. No outro, um deslocamento da discussão da natureza 
de sujeito e de escrita na alfabetização, um movimento de mudança na reflexão sobre esses conceitos.

Elegemos neste trabalho uma análise de escrita vinculada à Psicogênese, e, por conseguinte, a mesma escrita analisada à luz do Interacionismo Dialógico, buscando, mediante as teorizações pautadas, encaminhamentos que nos ajudassem a enxergar um pouco mais além. E foi a partir dessa Aquisição de Linguagem Interacionista de De Lemos, que externaliza uma noção de ressignificação do papel da alteridade no processo de aquisição da linguagem oral e escrita, que Borges (2006) chamou na escrita inicial da criança de "feixes de relações", uma vez que as crianças ainda não alfabetizadas mas que (re)conhecem as letras do alfabeto, escrevem a partir de uma cadeia de significantes. Sendo assim, ao escrever, a criança entra na ordem simbólica e dá sentido ao funcionamento linguístico da escrita.

As duas seções da fundamentação nos mostram visões distintas em campos diferentes do conhecimento. A princípio, nossas discussões teóricas discorreram a partir do viés em que o sujeito é consciente, manipula e mostra-se dono da linguagem. Posteriormente, nossas discussões pautaram-se em outra dimensão de olhar, a partir da linguagem enquanto sistema de funcionamento que captura a criança e desliza pelo inconsciente. O reconhecimento da natureza linguística da aquisição da escrita inicial nos permite olhar para essa escrita como uma emergência - mesmo que heterogênea, indeterminada, com efeito nonsense - do funcionamento da língua operando no sujeito.

As discussões feitas nos mostram o quanto cada teoria contribui no desenvolvimento de concepções acerca de sujeito, língua e linguagem ao longo dos tempos. A análise dos dados versou sobre uma descrição analítica de um mesmo texto nas duas visões teóricas, observando o que cada uma delas revela nos dados da escrita em análise.

Podemos afirmar que não existe especificamente problema nenhum em relação à determinada escolha de análise mediante o objetivo de cada professor, o que nos indaga é a oportunidade que se pode perder de entender o processo, as relações existentes, as cadeias de significantes que se fazem presentes nas produções e são deixadas (em muitos casos) à deriva. Pois, diante do apego a uma única teoria, fecham-se outras possibilidades de análises e de reflexões que também são importantes nesse processo.

Durante o desenrolar das discussões teórico e prática, esta última com maior fervor, embora tenhamos assumido uma postura investigadora apenas, não podemos falar de neutralidade, pois é possível afirmar que diante de um campo úbere de discussões acerca da aquisição da escrita, é necessário também outras possibilidades de análises de escritas de nossas crianças.

Para isso, formações continuadas para professores em outras dimensões são importantes. À aquisição da linguagem enquanto processo dialógico ressignificada pela Psicanálise cabe algumas ponderações importantes no processo de aquisição da escrita: um olhar investigativo das produções, a implicação subjetiva no contexto de desenvolvimento da escrita e outras possibilidades "mais". A ideia é compreender 
que, dependendo da escolha metodológica de análise utilizada - conforme nosso trabalho -, é perfeitamente possível e necessário "olhar mais", enxergar não só o que está na superfície da escrita, mas ir "além do horizonte".

Conhecedor de outras possibilidades de análises de escritas, o professor terá a oportunidade de escolher "conscientemente" qual caminho percorrer. Será uma escolha metodológica, o que difere totalmente quando não temos consciência delas. Isso faz toda a diferença nos efeitos de posicionamento do professor em suas análises de escritas iniciais de criança, o processo de alfabetização.

Os dados revelaram a riqueza de significações presentes nas produções das crianças, o que afasta radicalmente uma teoria da outra. Digamos que ao tentar delimitar as unidades linguísticas, mesmo quando se é tomada para análise a língua constituída, não nos é "possível" tratar de categorizações da escrita inicial. Os dados mostram que na visão psicogenética é difícil enquadrar as escritas nos níveis propostos por Ferreiro e Teberosky (2009). Os textos do corpus oscilam quanto a essas fases nos mostrando que o encaixotamento é algo problemático pelo próprio caráter heterogêneo e subjetivo da linguagem.

Buscamos mostrar também como a relação sujeito-escrita é atravessada por um funcionamento que escapa ao domínio do sujeito. Esse reconhecimento linguístico da aquisição da escrita inicial nos permite olhar a escrita como uma emergência, heterogênea e indeterminada do funcionamento da língua, operando no sujeito. Pudemos observar, dessa forma, que as análises nos permitem dizer que as escrituras infantis, de certa maneira, afastam uma escrita de um sujeito tido como psicologizante, aproximando-se bem mais robustamente de um processo de aquisição de linguagem escrita tendo como lugar de origem um sujeito imerso e sob efeito do funcionamento da linguagem, sempre.

Esperamos que este trabalho contribua nas discussões de professores e pesquisadores da área, para que a visão, o olhar e o enxergar do universo da aquisição da linguagem em lócus pedagógico possam também transacionar pelos sentidos que a crítica e as discussões em relação a aquisição da escrita podem permitir.

As ponderações levantadas até aqui nos mostraram que as discussões no campo da aquisição da linguagem têm sido marcadas fortemente pelos estudos psicogenéticos. Vislumbramos que esse trabalho possa contribuir para a reflexão teórica e prática também sob outra perspectiva e para a formulação de outras discussões (nossas e de outros).

\section{Referências}

BENVENISTE, É. Vista d'olhos sobre o desenvolvimento da linguística. In: Problemas de linguística geral, I. Campinas: Pontes. p. 19-33, 1966.

BORGES, S. O que gostaria de perguntar a Emilia Ferreiro sobreo sujeito na teoria psicogenética da alfabetização e não tive oportunidade. Inter-Ação, Goiania, 1999. 
A ordem sob a desordem: a escrita do delírio. Revista de Psicologia, Rio de Janeiro, vol. 1, no1, 2002

. Criança, corpo e linguagem: que(m) fala?. In: Caderno de Estudos Linguísticos. Campinas, 2005.

. A aquisição da escrita como processo linguístico. In: LIER-DE-VITTO,

FRANCISCA e ARANTES, L. Aquisição, patologias e clínica de linguagem. São Paulo: EDUC, FAPESP, 2006.

O quebra-cabeça: a alfabetização depois de Lacan. Goiânia, Ed. da UCG, 2006.

. A Psicanálise na alfabetização. Revista ACOALFA plp: Acolhendo a

Alfabetização nos Países de Língua portuguesa, São Paulo, ano 5, n. 9, 2010/ 2011.

Disponível em: <http:/ /www.acoalfaplp.net>. Publicado em: setembro de 2010 - março de 2011.

DE LEMOS C.T. G. "Sobre a especularidade como processo constituinte no diálogo e na linguagem da aquisição”. Em: CAMAIONI, L. e LEMOS, C. T. G. de. (org) Questões como explicações sociais: temas piagetianos reconsiderados. Amsterda: John Benjamins 1985

. A sintaxe no espelho. Cadernos de Estudos Linguísticos, 10 Campinas: IEL/ UNICAMP 1986(a).

Interacionismo e Aquisição de Linguagem. In: Revista DELTA, 2. São Paulo: PUC-SP. 1986(b).

. Os processos metafóricos e metonímicos como mecanismos de câmbio. Substratum/Artes Médicas, 1992.

Da morte de Saussure, o que se comemora? In: Psicanálise e Universidade,1995.

. Em busca de uma alternativa à noção de desenvolvimento na interpretação do processo de Aquisição de Linguagem. Relatório de Pesquisa. IEL, UNICAMP, 1999.

. Sobre o Estatuto Lingüístico e Discursivo da Narrativa na fala da criança. Linguística, 2002.

Das vicissitudes da fala da criança e de sua investigação. Caderno de Estudos Linguísticos, 2002.

. Uma critica (radical) a noção de desenvolvimento na Aquisição de Linguagem. In: LIER-DE-VITTO, F.; A. L. Aquisição, patologias e clínica de linguagem. São Paulo: EDUC, FAPESP, 2006. 
DOLZ, J.; NOVERRAZ, M.; SCHNEUWLY, B. Sequências didáticas para o oral e a escrita: apresentação e um procedimento. In: SCHNEUWLY, B.; DOLZ, J. ET. AL. Gêneros orais e escritos na escola. Tradução e organização de R. H. R. Rojo e G. S. Cordeiro. Campinas: Mercado das Letras. 2004.

FARIA, N. R. B. Nas letras das canções, a relação oralidade-escrita. Maceió: EDUFAL, Recife: EDUFPE, 1997.

- A letra sob as palavras da letra. Leitura Revista do Programa de Pós Graduação em Letras (UFAL), Maceió - AL, 1997.

FERREIRO, E. Reflexões sobre alfabetização. 24. ed. São Paulo: Cortez, 2001.

Desenvolvimento da Alfabetização: Psicogênese. In: GOODMAN,Y.

M.(Org.). Como as Crianças Constroem a Leitura e a Escrita: perspectivas piagetianas. Porto Alegre: Artes Médicas, 1995

FERrEIRO, E. \& TEBEROSKY, A. A Psicogênese da língua escrita. Porto Alegre: Artmed, 1999.

JAKOBSON, R. Lingüística e Comunicação. São Paulo: Cultrix, 1971.

LACAN, J. O Seminário, livro 1. Os escritos técnicos de Freud. Rio de Janeiro: Jorge Zahar Editor, 1983.

. A instância da letra no inconsciente ou a razão desde Freud. In: Escritos. Rio de Janeiro: Jorge Zahar, 1998.

LEMOS, M. T. G. A-língua que me falta: uma análise dos estudos em Aquisição da Linguagem. Tese (Doutorado) - Instituto de Estudos da Linguagem, UNICAMP, Campinas, 1994.

A língua que me falta. Campinas: Mercado de Letras/FAPESP. 2002.

MORAIS, A. G. Sistema de escrita alfabética. São Paulo: melhoramentos, 2012.

PIAGET, J. Psicologia e epistemologia: por uma teoria do conhecimento. Rio de Janeiro: Forense, 1973.

SAUSSURE, F. Curso de Lingüística Geral. São Paulo: Cultrix, 1975.

Curso de Linguística Geral [1916]. Tradução Antônio Cheline, José Paulo Paes, IzidoroBlikstein. 27 ed. São Paulo: Cultrix 2006.

SOARES, Magda. Alfabetização e letramento. 5 ed. São Paulo: Contexto, 2008.

VYGOTSKY, L. S. Linguagem, Desenvolvimento e Aprendizagem. São Paulo, Ícone e EDUSP, 1988.

WEISZ, T. O diálogo entre o ensino e a aprendizagem. 2. ed. São Paulo: Ática, 2009. 